\title{
Experimental analysis and research on flexural properties of reinforced concrete composite beams
}

\author{
Ruqiang Xie ${ }^{1, *}$,Yuanchao $\mathrm{Hu}^{1}$, and Xiaopu Shen ${ }^{1}$ \\ ${ }^{1}$ Key Lab. of Building Structure of Anhui Higher Education Institutes, Anhui Xinhua University, Hefei 230088, China
}

\begin{abstract}
In order to further study the flexural properties of reinforced concrete beams after composite reinforcement, three composite beams and one cast-in-situ beam were tested under static load focusing on the bearing capacity, the law of crack development and the change of deflection. Test results demonstrate the yield strength, ultimate bending strength, and deflection of the composite beams are similar to those of the cast-in-situ beam, which confirms that the reinforced concrete composite beams can be used for reinforcement purposes in engineering projects.
\end{abstract}

\section{Introduction}

Reinforcement technology has been widely used in engineering projects. Wang Chunyang ${ }^{[1]}$ from Huazhong University of science and technology and Deng Zongcai ${ }^{[2]}$ from Tsinghua University have reinforced the concrete with carbon fiber, while Ouyang Lijun ${ }^{[3]}$ utilized the basalt fiber for reinforcement. All the above measures greatly improve the flexural property of the beam. Besides, Zeng Xiantao ${ }^{[4]}$ reinforced the beam using glass fiber, which greatly improved the bearing capacity and aseismatic performance of the beam. In recent years, the shock absorption technology has developed rapidly. Scholars from Harbin Institute of Technology ${ }^{[5]}$ and Southeast University ${ }^{[6]}$ have made in-depth studies on the damper. Also, Zhao Junxian ${ }^{[7]}$ and Shen Xiaopu ${ }^{[8]}$ used buckling braces to absorb and dissipate seismic energy and reduce the seismic response of structures or components.Wang Lei [9] has studied some major experimental parameters including changing patterns of cracking and deflection, the ultimate bearing capacity and failure mode of the reinforced concrete composite beams with added reinforced steel at the tension zone. Their study results showed that the bearing capacity of the composite beam reinforced from the bottom is similar to that of the cast-in-situ beam. In this paper, the composite beam reinforcement method is adopted to increase the height of the beam to improve the flexural property and bearing capacity of the concrete beam for better reinforcement.

\section{Experimental program}

Four reinforced concrete beams were tested under static load to failure. The cast-in-situ beam specimen was recorded as ZJL, and three composite beam specimens were recorded as DHL1, DHL2 and DHL3 respectively. The concrete strength of the specimens is $\mathrm{C} 25$, and the steel rebar is HRB335.

\subsection{Test specimens}

All the beams with a width $b=150 \mathrm{~mm}$, a height $\mathrm{h}=300 \mathrm{~mm}$, and $2400 \mathrm{~mm}$ length were cast for four point bending tests. The detail sizes of test specimens were designed and the strain gauges were pasted as shown in Fig.1 and Fig.2. The four steel strain gauges were arranged at the mid-span of the lower duplex reinforced

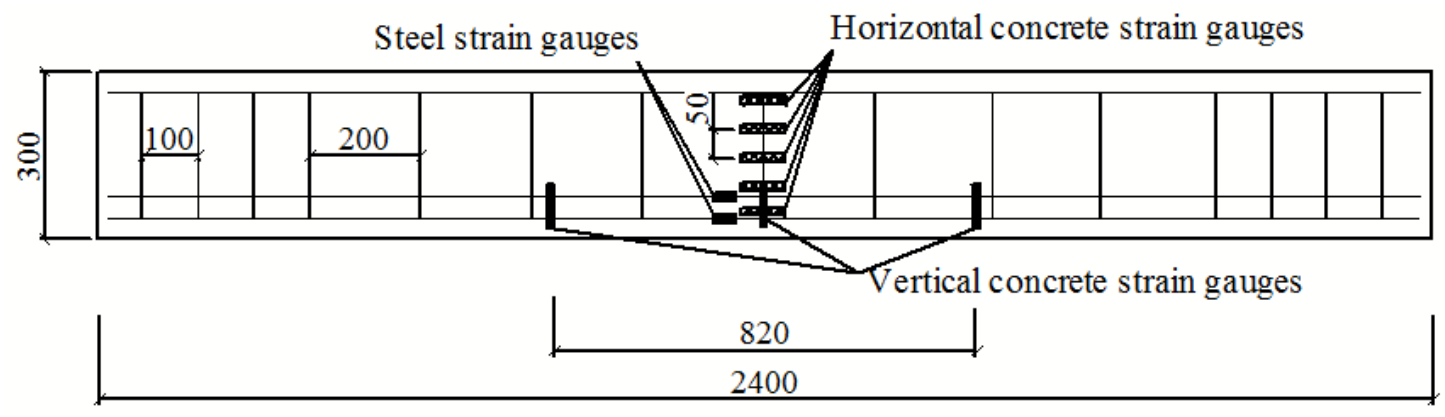

Fig.1. Processing of the beams and layout of strain gauges

\footnotetext{
* Corresponding author: hitor@126.com
} 


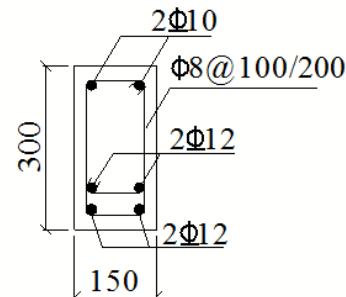

(a)

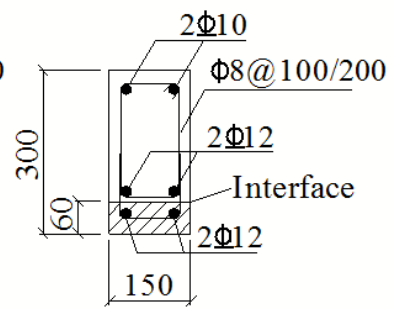

(b)
Fig.2. Beam cross-section (a)cast-in-situ beam; (b)Composite beam

Before pouring the composite beams, put the bottom of steel reinforcement cages up. The composite beams were prepared by pouring the concrete for $240 \mathrm{~mm}$ and then for $60 \mathrm{~mm}$. Some scratches were made on the surface before concrete set for good interaction between upper and lower layers.

\subsection{Experimental approach}

The static test was carried out on the self-balance servo loading control system. Experimental set-up is shown in Fig. 3(a). The horizontal load remains constant during the tests, and the vertical load was applied by the electro-hydraulic servo actuator and acts at $1 / 3$ of the mid-span with a distributive girder (see Fig.3(b)).

During the tests, a built-in displacement meter of the actuator was used to measure the vertical displacement of the cast-in-site beam and the composite beams. Besides, the values of the vertical load and displacement were automatically recorded by the loading control system. External displacement meters were placed in the mid-span and $350 \mathrm{~mm}$ away from the mid-span under the beam to measure the bending deformation.

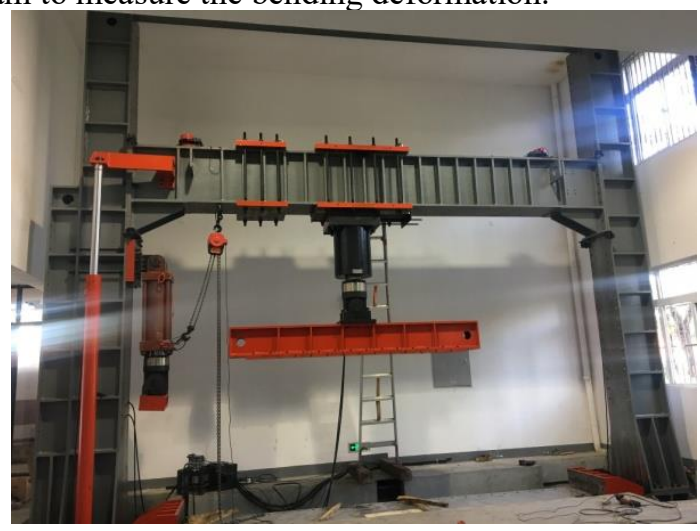

(a)

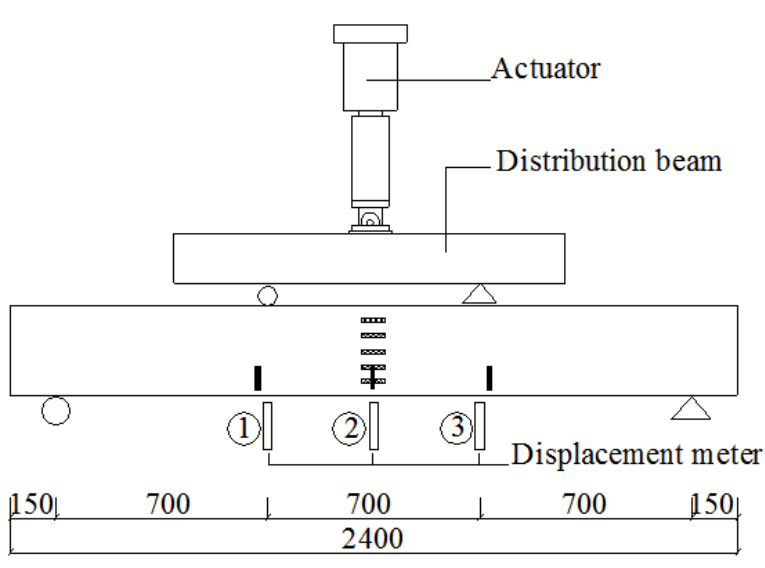

(b)

Fig.3. Experimental set-up (a) The self-balance servo loading control system ;(b) Four-point loading of beam

According to the Specification for Seismic Test of Buildings (JGJ/T 101-2015) ${ }^{[10]}$, the specimens should be preloaded twice before the formal loading, and the preload is not higher than $30 \%$ of the cracking load. The vertical loading mode was uniaxial monotonic loading, and the loading system was hybrid control loading, which was carried out in two stages. The first stage (elastic stage) was controlled by force-loading with a rate of constant $0.2 \mathrm{kN} / \mathrm{s}$ and the second stage was controlled by displacement loading after specimens yield.

\section{Experimental results and discussion}

\subsection{Bearing capacity analysis}

Failure process under loading is provided in Table 1. The failure modes are shown in Fig 4. The cracking load of the cast-in-situ beam is larger than those of the composite beams. For composite beams, the average yield load and ultimate load are $106.7 \mathrm{kN}$ and $116 \mathrm{kN}$ respectively, which are slightly lower than that of the cast-in-situ beam.

Table 1. Loading failure process of beams

\begin{tabular}{cccc}
\hline Beam code & Cracking load & Yield load & Ultimate load \\
\hline ZJL & $24 \mathrm{kN}$ & $108 \mathrm{kN}$ & $118 \mathrm{kN}$ \\
DHL1 & $20 \mathrm{kN}$ & $104 \mathrm{kN}$ & $113 \mathrm{kN}$ \\
DHL2 & $16 \mathrm{kN}$ & $110 \mathrm{kN}$ & $121 \mathrm{kN}$ \\
DHL3 & $20 \mathrm{kN}$ & $108 \mathrm{kN}$ & $114 \mathrm{kN}$ \\
\hline
\end{tabular}




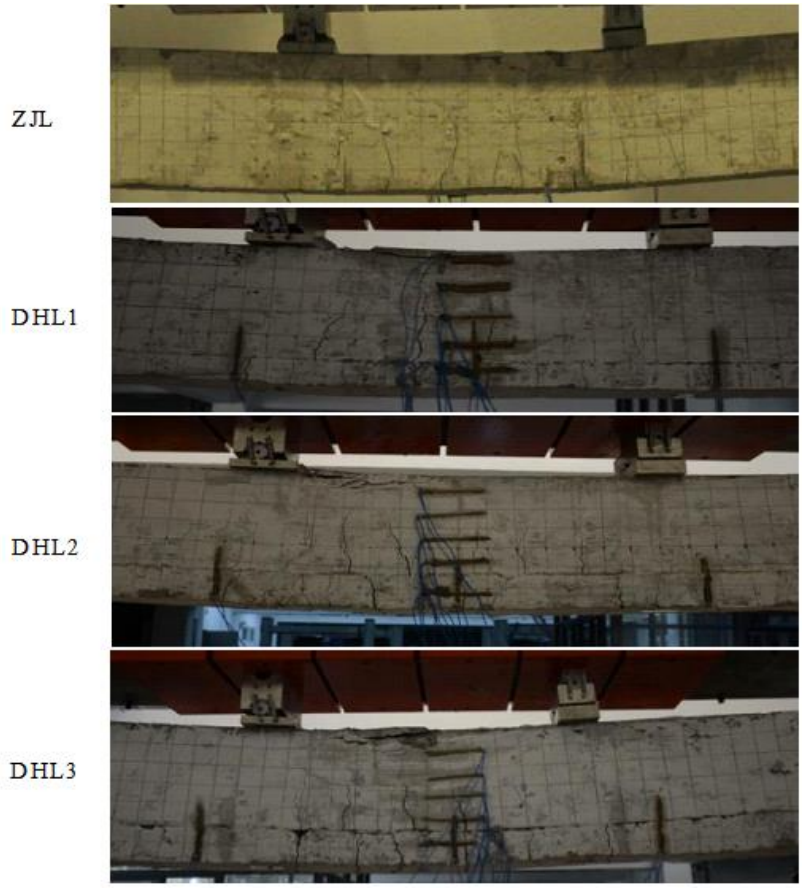

Fig.4. Failure mode of beams

\subsection{Cracking behavior analysis}

The first cracks appeared in the pure-bending regions and near the mid-span. As the loading was further increased, new cracks appeared both in pure-bending regions and in shear-bending regions. When load was up to $40 \mathrm{kN}$, some cracks developed upward from the interface of composite beams. The results of crack for all tested specimens are detailed in Table 2, where cracking load and crack width are presented. In Table 2, the word left indicates that a crack at somewhere on the left side from the mid-span and vice versa.

Table 2. Cracking behavior of the first cracks

\begin{tabular}{|c|c|c|c|c|c|}
\hline \multirow[b]{2}{*}{$\begin{array}{l}\text { Beam } \\
\text { code }\end{array}$} & \multicolumn{4}{|c|}{ Crack width(mm) } & \multirow[b]{2}{*}{$\begin{array}{l}\text { Location } \\
(\mathrm{mm})\end{array}$} \\
\hline & $\begin{array}{c}\text { Cracking } \\
\text { load }\end{array}$ & $40 \mathrm{kN}$ & $60 \mathrm{kN}$ & $\begin{array}{l}\text { Yield } \\
\text { load }\end{array}$ & \\
\hline ZJL & 0.04 & 0.10 & 0.19 & 0.70 & 60 \\
\hline DHL1 & 0.16 & 0.18 & 0.32 & 0.42 & 90 right \\
\hline DHL2 & 0.12 & 0.19 & 0.28 & 0.56 & $100 \mathrm{left}$ \\
\hline DHL3 & 0.28 & 0.36 & 0.44 & 0.58 & left \\
\hline
\end{tabular}

In Table 2, it can be observed that the crack width of the cast-in-situ beam is narrower than those of composite beams. However, from $60 \mathrm{kN}$ to yield load, the crack width of cast-in-situ beam increases rapidly and exceeds those of composite beam because of the interface.

Before yielding, the cracks of composite beams were evenly distributed above and below the interface and showed little tendency towards transfixion; after yielding, there was an obvious tendency towards transfixion between the upper and lower cracks. The distribution of cracks is shown in Figure 5.
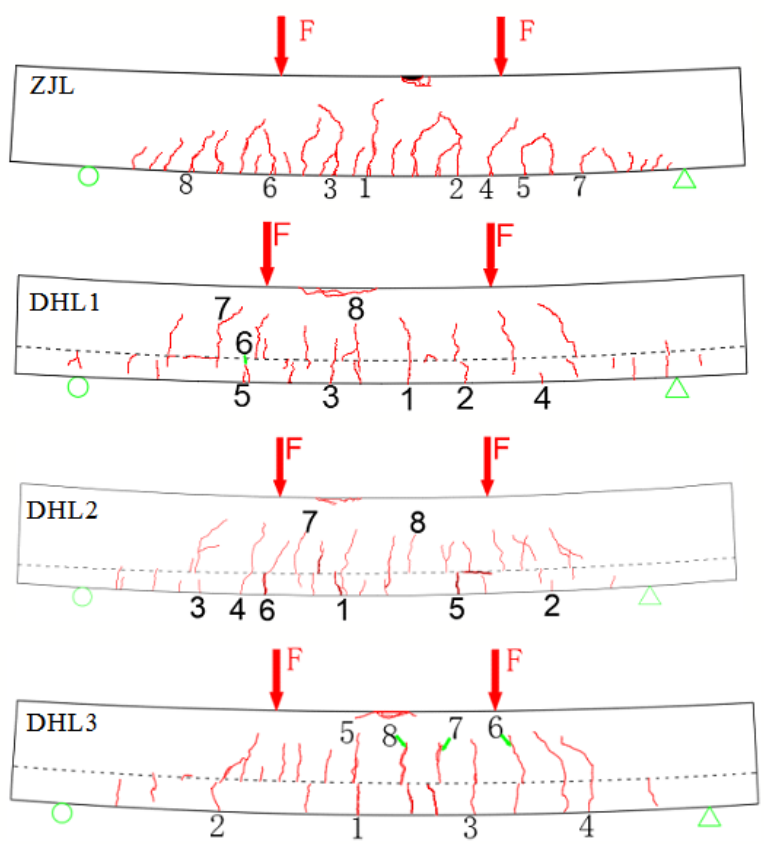

Fig.5. Crack distribution diagram

\subsection{Load vs deflection response}

When the longitudinal steel rebars at the bottom part of the beam were yielding, the load mode controlled by displacement was adopted. When the displacement reached $20 \mathrm{~mm}$, the cracks of ZJL, DHL1, DHL2 and DHL3 continue to extended upwards, with a transient sound of concrete cracking. In this case, the beams were obviously bent and the deflection increased. When the displacement of ZJL, DHL1, DHL3 was increased to 25 $\mathrm{mm}$ and that of DHL2 was increased to $30 \mathrm{~mm}$, the deflection of the beam increases, the bending becomes more salient. As a result, the upper concrete was crushed and the lower composite layer and interface were broken to varying degrees. As a consequence, the test specimens were in failure. The load vs deflection curve is shown in Fig.6.

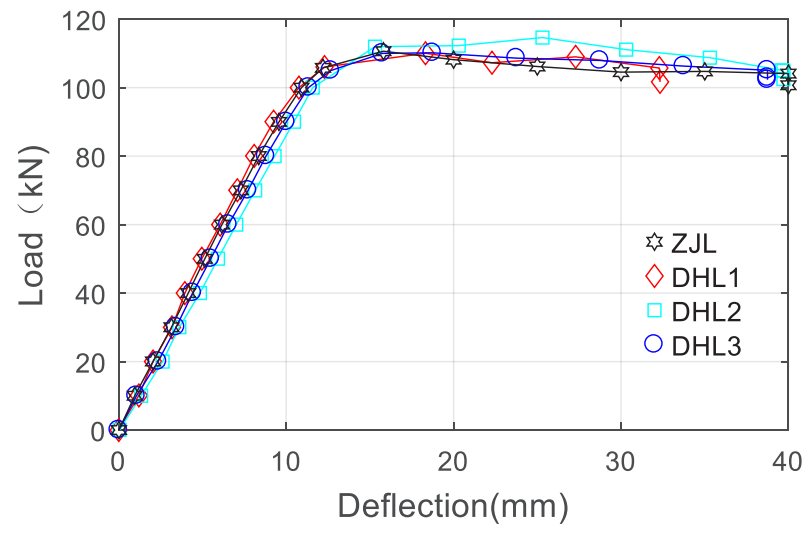

Fig.6. Load vs deflection response for beams

The deflection of composite beam DHL1 is similar to that of the cast-in-site beam in the linearly elastic stage, while the deflection of DHL2 and DHL3 is slightly larger than that of the cast-in-site beam: $0.93 \mathrm{~mm}$ and 
$0.49 \mathrm{~mm}$ larger when the load reaches $80 \mathrm{kN}$, and 0.99 $\mathrm{mm}$ and $0.74 \mathrm{~mm}$ larger when the load rises to $100 \mathrm{kN}$.

\section{Conclusions}

The experiment of four beams tested under four-point monotonic static load to failure is described in this article. Strength, crack and deflection are compared and analyzed. Within the observation scope of the experiment, the following conclusions can be drawn:

(1) The cracking loads of composite beams were less than that of cast-in-situ beam. The mid-span cracks of composite beams, which initial width were greater than that of cast-in-situ beam, increase slowly. At yield load, the crack width of cast-in-situ beam became the biggest one.

(2) The test results show that the average value of yield load and ultimate load of composite beams are slightly smaller than, but close to, those of the cast-in-site beam. Thus, the composite beam can achieve a similar loading capacity to the cast-in-site beam.

(3) Under the same load, the average deflection of the composite beam is slightly larger than that of the cast-in-site beam and the difference is not significant. Therefore, the reinforced composite beam can achieve deformation-resistant performance similar to the cast-in-site beam that has the same cross-section and is made from the same materials.

\section{Acknowledgement}

The authors acknowledge that this work was supported by the Key Projects of Anhui Province University Outstanding Youth Talent Support Program (No. gxyqZD2016390), Anhui Provincial Quality Engineering Project (No. 2019rcsfjd089 and No. 2016tszy042), and the Key Pprojects of Anhui Xinhua University (No. 2015zr002).

\section{References}

1. Chunyang Wang, J. WuHan Univ. Technol., 31, 91(2009)

2. Zongcai Deng, Chin. J. High. Tran., 14,45(2001)

3. Lijun OuYang, Bin Ding, Zhoudao Lu, Fiber Reinf. Plast./Compos., 84(2010)

4. Xiantao Zeng, Yahong Ding, Huimin Li, Fiber Reinf. Plast./Compos., 3(2007)

5. Zhengqiang Ye, Aiqun Li, Youlin Xu, J. Southeast Univ., 32, 466(2002)

6. Bin Wu, Jigang Zhang, Jinping Ou, J. Build. Struc., 24,7(2003)

7. Junxian Zhao, Bin Wu, Jinping Ou, Chin. Civil Eng. J., 44, 441(2011)

8. Xiaopu Shen, Yu Zhang, Ruqiang Xie, Steel Cons., 34, 9(2019)

9. Lei Wang, Xiaochuan Peng, Build. Struc., 43, 51(2013)
10. JGJ/T 101-2015, Specification for Seismic Test of Buildings (2015) 